\title{
Fuel Injection and Flame Stabilization in a Liquid-Kerosene-Fueled Supersonic Combustor
}

\author{
G. Yu, ${ }^{*}$ J. G. Li, ${ }^{\dagger}$ X. Y. Chang,,${ }^{\ddagger}$ and L. H. Chen ${ }^{\S}$ \\ Chinese Academy of Sciences, 100080 Beijing, People's Republic of China \\ and \\ C. J. Sung ${ }^{\mathbb{I}}$ \\ Case Western Reserve University, Cleveland, Ohio 44106
}

\begin{abstract}
Investigations on combustion enhancement and stabilization of liquid kerosene using five different integrated fuel-injection/cavity-based flameholder configurations were conducted in a model combustor of cross sections $51 \times 70 \mathrm{~mm}$. The entry Mach number was fixed at 2.5, whereas the ranges of total pressure and stagnation temperature varied were 1.0-1.3 MPa and 1700-1900 K, respectively. Pure liquid atomization and barbotaged atomization with either air or hydrogen were compared based on spray-structure visualization and combustionperformance assessment. The effects of kerosene injection angle and cavity configuration on both flameholding and mixing enhancement were also investigated. Experimental results showed that the average increase in combustion efficiency using hydrogen barbotage is $15 \sim 20 \%$ as compared to the use of pure liquid atomization, for the conditions investigated. Cavity configuration with combined open-closed cavities was demonstrated to have better combustion performance than the single-cavity module. It was also shown that kerosene injection location and injection scheme have strong effects on the minimally required pilot hydrogen equivalence ratio. The present results further substantiate our previous finding that there existed a local high-temperature region, which would be the major factor in promoting the ignition and the subsequent flameholding of the kerosene combustion.
\end{abstract}

\section{Introduction}

$\mathbf{C}$ OMPARED to hydrogen, energy density and handling issues render liquid hydrocarbons as attractive candidates for fueling the scramjet in the lower hypersonic flight regime. However, the realization of liquid-hydrocarbon-fueled scramjets would require a number of scientific and technical problems to be resolved. For instance, the relatively long ignition delay time of hydrocarbonfuel could substantially exceed the residence time of gas flow within combustors. Additionally, the use of liquid hydrocarbons requires quick vaporization prior to the mixing and combustion. Therefore, the challenging issues leading to successful operation of a scramjet include fast evaporation of liquid spray, effective fuel-air mixing, ignition enhancement, and combustion stabilization in supersonic flows. ${ }^{1,2}$

Considerable efforts (e.g., Refs. 3-16) have focused on the issues of liquid-hydrocarbon fuel injection in supersonic crossflows and effective approaches in achieving flame stabilization. It has been recognized that a supersonic liquid-hydrocarbon-fueled combustor of high performance requires 1) a deeper fuel penetration into the airstream for better mixing; 2) generation of smaller liquid fuel droplets for faster evaporation; 3) an appropriateflame-stabilization mechanism for piloting and sustaining combustion; and 4) a substantial reductionin drag losses associated with processes of mixing and flameholding.

Received 5 April 2002; revision received 24 February 2003; accepted for publication 15 May 2003. Copyright (C) 2003 by the American Institute of Aeronautics and Astronautics, Inc. All rights reserved. Copies of this paper may be made for personal or internal use, on condition that the copier pay the $\$ 10.00$ per-copy fee to the Copyright Clearance Center, Inc., 222 Rosewood Drive, Danvers, MA 01923; include the code 0748-4658/03 \$10.00 in correspondence with the CCC.

*Professor, Institute of Mechanics, 15 Zhongguancun Road, Haidian District; yugong @ mail.imech.ac.cn. Member AIAA.

†Professor, Institute of Mechanics; jgli@mail.imech.ac.cn. Member AIAA.

*Professor, Institute of Mechanics; changxy @ mail.imech.ac.cn. Member AIAA.

$\S$ Associate Professor, Institute of Mechanics; lhchen@mail.imech.ac.cn.

${ }^{\mathbb{T}}$ Associate Professor, Department of Mechanical and Aerospace Engineering; cjs15@po.cwru.edu. Senior Member AIAA.
In terms of ignition enhancement, many studies ${ }^{4-7}$ have demonstrated that a hydrogen pilot flame can provide a reaction zone with high temperature and a large radical pool so that the subsequent hydrocarbon ignition is enhanced. Regarding flame stabilization, applying the wall cavities as a flameholding mechanism in supersonic combustors has been reported by several research groups. ${ }^{8-10,14,15}$ The cavity-based integrated configuration, including fuel injectors and flameholder, has been shown to possess a great potential to achieve active flame stabilization in supersonic combustors. In particular, the liquid fuel can be injected eitherupstream or at the floor of the wall cavity for enhancing mixing and shortening ignition delay time. Moreover, the wall injection can greatly simplify the overall design of combustor and cooling system in practical applications, as compared to the in-stream devices. Furthermore, a number of studies including ours ${ }^{16}$ have demonstrated that the cavity-based integrated configuration indeed improves the combustor performance drastically. Especially, with a cavity, a high-temperature, low-speed recirculation, reaction zone can be established to serve as a pilot flame, which can in turn reduce the bulk ignition delay time and sustain a stable combustion.

To date, the physical mechanism of the effects of cavity-based flameholder on supersonic combustion remains an interesting subject. For example, the key parameters characterizing open/closed cavities and stable/unstable cavities in reacting flows have not been well explored. In particular, the effects of cavity on mixing and combustion can be quite disparate depending on whether the cavity is open or closed. However, the conventional definition of the cavity characteristics was based on the nonreacting flows. Our previous results ${ }^{16}$ have suggested that the existing definition is subject to revision in the reacting flows. Moreover, Yu et al. ${ }^{8}$ have systematically investigated the stable and unstable characteristics of a cavity flow with an emphasis on the phenomena of flow-induced cavity resonance. It was found ${ }^{8}$ that the stable and unstable cavities could be used for flameholding and mixing enhancement, respectively. As such, combined open-closed cavities in tandem would be a promising approach to provide both flameholding and mixing enhancement.

In terms of injection scheme and mixing enhancement involving liquid hydrocarbons, two basic requirements are 1) the size of liquid fuel droplet generated must be sufficiently small for faster 
evaporation and 2) the fuel penetrationinto the supersonic airstream has to be as deep as possible for better mixing. Effervescentatomization, in which gas bubbles are introduced to the liquid fuel, has been proposed. As a result, a turbulenttwo-phase flow is generated, which can improve the penetration and atomization of the fuel jet spray. Although this approach seems to be a viable concept, its application in liquid-fueled supersonic combustion has not yet been extensively investigated. Avrashkov et al. ${ }^{3}$ first applied the effervescent-type injector to improve the atomization and mixing of kerosene jet in a model supersonic combustor. However, there was no systematic investigation on spray structure of aerated liquid fuel jet reporting therein. Recently, Lin et al. ${ }^{11}$ employed the effervescent atomization technique to examine the phenomena of liquid fuel injection into a supersonic crossflow. Their results showed that the overall breakup process for pure liquid mode spray is slow, and hence long axial distance is needed for the generation of fine droplets. On the contrary, for high levels of barbotage, namely, the so-called barbotage mode spray, the liquid break processes occur immediately after or even before the liquid is discharged because of the highly turbulent features of this inhomogeneous two-phase flow and the expansion caused by a high-pressure barbotage gas. ${ }^{11}$ Besides, the overall spray penetration height in the barbotage mode increases with increasing amount of barbotage gas. ${ }^{11}$

Mathur et al. ${ }^{12}$ extended the work of Lin et al. ${ }^{11}$ to study the combustion characteristics of warm liquid JP-7 in a supersonic combustor using a cavity-based fuel-injector/flameholder concept with oxygen barbotage. It was demonstrated in Ref. 12 that the aerating effect of the barbotage gas indeed facilitates combustion and that with oxygen-assisted barbotage the mainstream combustion was successfully sustained even after the ignition sources in the cavity, including a spark plug and a plasma torch, were turned off.

Because the effervescent atomization technique seems to be a viable approach for combustion enhancement as a result of the deeper fuel penetration and faster vaporization of liquid spray, the present investigation extends our previous studies on pilot $\mathrm{H}_{2}$ injection and wall-cavity flameholders to examine the effects of effervescent atomization on supersonic combustion systematically. Experiments were conducted using a combustor of cross section of $51 \times 70 \mathrm{~mm}$ with a fixed entry Mach number of 2.5 , at various stagnation conditions and global equivalence ratios. Specifically, five types of integrated wall injectors/cavity-basedconfigurations, with and without effervescent atomization, were designed and tested for comparison. The stagnation temperatures of vitiated air were varied from 1700 to $1900 \mathrm{~K}$, and its stagnation pressures ranged from 1.0 to 1.3 MPa. Visualization of the atomization, penetration, and spreading of a kerosene jet spray in a Mach 2.5 crossflow was also carried out with and without gas barbotage.

In addition, the present study aims to investigate further the cavity flow in both open and closed cavities. Especially, the characteristics of stable and unstable cavities in reacting flows are of particular interest. Two cavities in tandem, consisting of one open cavity and one closed cavity, for providing both flameholding and mixing enhancement were tested. Furthermore, based on the measured staticpressure distribution inside the combustor, a one-dimensional analysis developed previously ${ }^{17,18}$ was used for the data reduction and assessment of the combustor performance.

The experimental details of the investigation are presented in the next section. A one-dimensionalmodel employed for data reduction and analysis will be briefly described, which is followed by results and discussion.

\section{Experimental Considerations}

\section{Facility and Experimental Specifications}

Vitiated Air Supply System

High-temperature vitiated air was provided by burning hydrogen, oxygen, and air in a heater with the resulting oxygen volume fraction equal to that of the normal air. The system was controlled by a computer and capable of supplying heated air up to a flow rate of $2.0 \mathrm{~kg} / \mathrm{s}$, stagnation temperature of $2100 \mathrm{~K}$, and stagnation pressure of $4.5 \mathrm{MPa}$. The airflow was then accelerated to Mach 2.5 with a two-dimensionalnozzle. All of the flow rates were metered by sonic nozzles. The uncertainty associated with the flow-rate measurement was estimated to be within 3\%. Details of this facility were described by Li et al. ${ }^{19}$

\section{Combustor Configurations}

Figure 1 shows the schematic of the model combustor that had an entrance cross section of $51 \times 70 \mathrm{~mm}$. It was composed of four
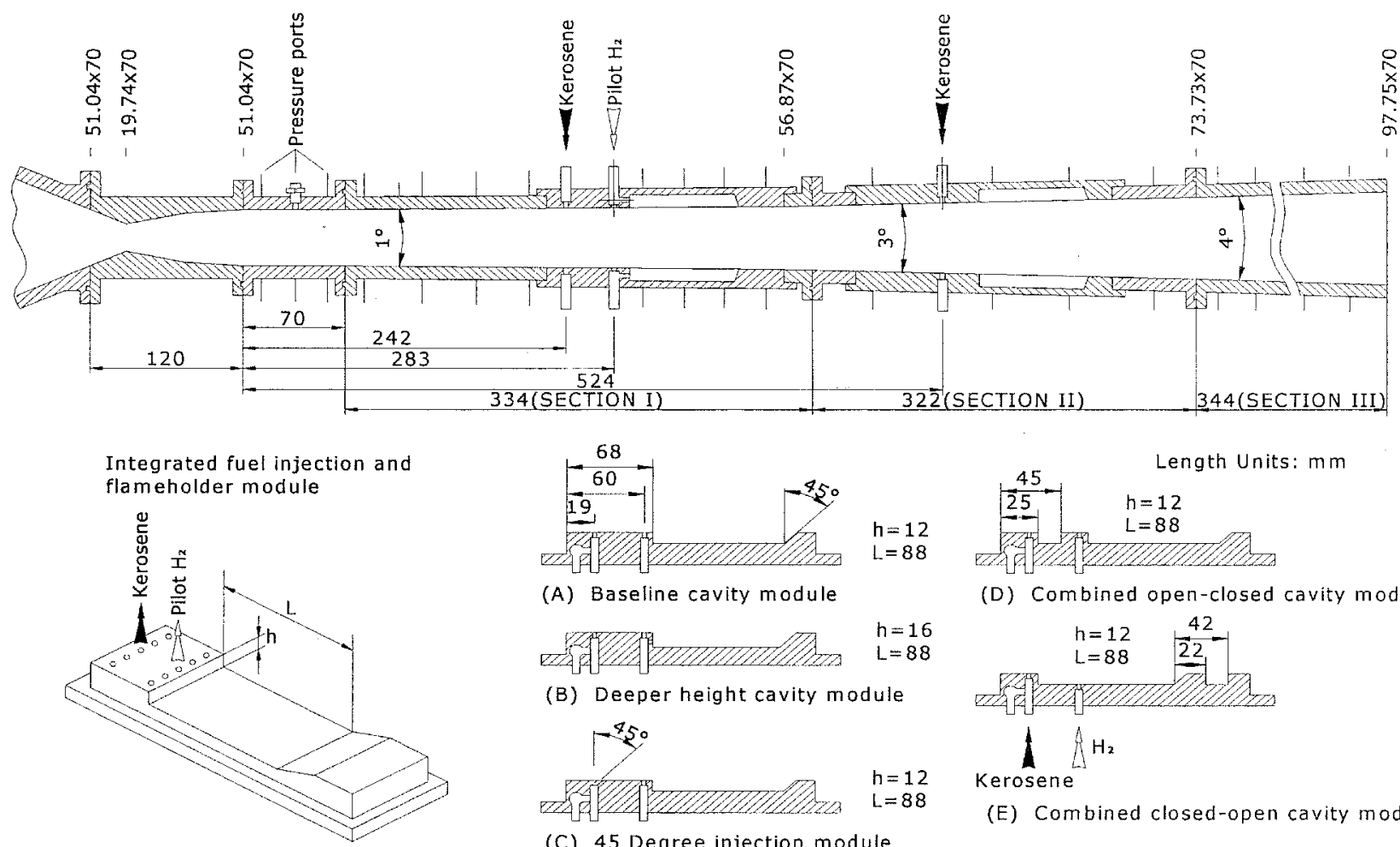

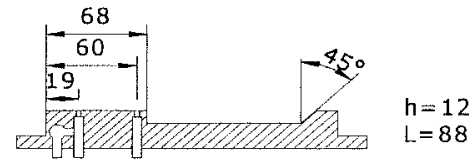

(A) Baseline cavity module

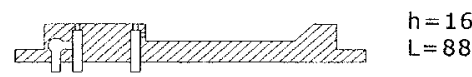

(B) Deeper height cavity module

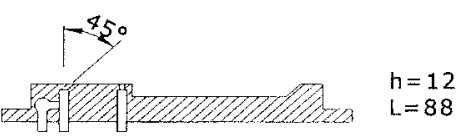

(C) 45 Degree injection module

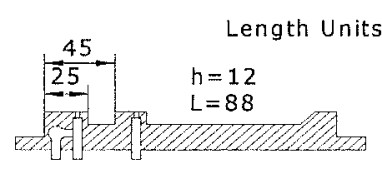

(D) Combined open-closed cavity module

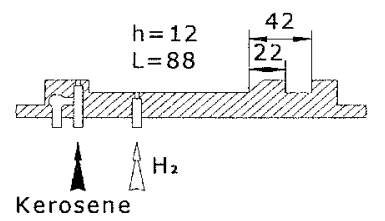

(E) Combined closed-open cavity module

Fig. 1 Schematic of a kerosene/pilot hydrogen supersonic model combustor and the associated interchangeable, integrated cavity modules. All length dimensions are in $\mathbf{~ m m}$. 
sections, including a removable, constant cross-section isolator of $70 \mathrm{~mm}$ length, a nearly constant-area section (1-deg divergence for boundary-layer corrections) of $334 \mathrm{~mm}$ length (section I), and two expansion sections (sections II and III). The first expansion section (section II) was of $322 \mathrm{~mm}$ length and had 3-deg divergence, whereas the second expansion section (section III) was of $344 \mathrm{~mm}$ long with 4-deg divergence.

The systems of pilot injectors and recessed flameholder cavities were designed to be composed of interchangeable, integrated modules in order for flexible variations of system configuration. Identical cavity modules were flush mounted on the top and bottom walls of the combustor in either section I only or both sections I and II. Both kerosene and pilot hydrogen were injected through the cavity module pair located in section I. When the second pair of cavity modules was also installed in section II, only kerosene was injected via the cavity modules therein. According to our earlier results, the depth $h$ and the cavity length $L$ of the baseline cavity module (A) were selected as $h=12 \mathrm{~mm}$ and $L=88 \mathrm{~mm}$, respectively. Cavity modules (C), (D), and (E) had the same $h$ as cavity module (A), whereas the cavity depth of cavity module (B) was increased to be $16 \mathrm{~mm}$. In addition, cavity modules (A), (B) and (C) were of singlecavity configuration with $L=88 \mathrm{~mm}$, whereas cavity modules (D) and (E) were of configuration with two cavities in tandem. The two different cavity lengths used in cavity modules (D) and (E) were 20 and $88 \mathrm{~mm}$. Based on the conventional definition, the shorter and longer ones correspond to open and closed cavities, respectively. Moreover, cavity modules (D) and (E) have a reverse order in terms of the cavity placement. For all five cavity modules the aft-ramp angles were fixed as 45-deg.

Furthermore, except cavity module (C) with a 45-deg angle injection, kerosene was injected normally into the airflow at the upstream of cavity. The present injection location of kerosene is different from our previous experiment, ${ }^{16}$ in which kerosene was injected mostly near the trailing edge of the cavity. Additionally, when there were cavity modules installed in both sections I and II there were two stations of kerosene injectors, located at 242 and $524 \mathrm{~mm}$ downstream of the combustor entrance. The pilot hydrogen injection was located at $283 \mathrm{~mm}$ downstream of the combustor entrance and was accomplished via five orifices of $1.0 \mathrm{~mm}$ diam normal to the airflow. As such, the injection locations of pilot hydrogen of cavity modules (A-D) were located upstream of the closed cavity, whereas that of cavity module (E) had the injector exit flush with the floor of the closed cavity.

Figure 2 shows the injection system for liquid kerosene and barbotage gas. Five equally spaced barbotage injectors with the same exit orifice diameter ranging from 0.4 to $0.8 \mathrm{~mm}$ were distributed along the wall width of $70 \mathrm{~mm}$, as shown in Fig. 2a. Each barbotage injector consisted of an internal tube with a diameter of $1 \mathrm{~mm}$ and an external tube with a diameter of $4 \mathrm{~mm}$. The inner tube was for kerosene passage, whereas the barbotage gas flowed through the annular gap between the tubes. The distance between the end of the internal tube and the exit orifice varied from 8 to $15 \mathrm{~mm}$. Figure $2 \mathrm{~b}$ also sketches the delivery system of liquid kerosene and barbotage gas. Kerosene was stored in a cylinder and pumped through a piston to achieve a desired pressurized state. The piston was driven by pressurized nitrogen that was regulated through nitrogen supply, regulators, pressure sensor, and two solenoid valves for quick turn on/off and release of high-pressure nitrogen. The barbotage gas (either air or hydrogen) was supplied through a high-pressure gas cylinder controlled by regulators, solenoid valve, pressure sensor, orifice of $1.2 \mathrm{~mm}$ diam, and a one-way valve. Flow rate of the barbotage gas was determined based on the pressure difference between upstream and downstream of the orifice through calibration. Kerosene flow rate was measured by the actual amount of kerosene released from the kerosene cylinder divided by the time elapsed. The operation sequence of the barbotage system was controlled by a computer through four solenoid valves.

\section{Pressure Measurements}

Static pressures were measured along the axial direction of the flowpath. There were 24 pressure ports arranged along each side wall of the model combustor. To obtain a mean axial-pressure distribution, pressure data of two sidewalls measured at the same axial location were averaged. Motorola MPX2200 0-0.5-MPa pressure sensors were used to detect the static-pressure signal. The uncertainty associated with the static-pressure measurement was estimated to be within $2 \%$.

The stagnation pressure of vitiated air in the heater was measured by using a CBY-21S 0-6-MPa pressure sensor manufactured by Zhong Hang Machinery and Electron Technology Corporation, with experimental error being within $2 \%$. Moreover, the total pressure at the exit of the model combustor was measured by using the watercooled pitot probes. The pressure sensor employed was Sensym $19 \mathrm{CIU} 3000 \sim 1.5 \mathrm{MPa}$. The experimentalerror in this total pressure measurement was within $3 \%$.

\section{Stagnation Temperature Measurements}

The stagnation temperature $T_{0}$ was measured by B-type thermocouples with corrections of radiation, conduction, and thermal inertia. The measured $T_{0}$ was further compared with the computed value based on the measured stagnation pressure and reactant flow rates. The experimental error in the stagnation temperature measurement was within $3 \%$ for $T_{0}<2000 \mathrm{~K}$.

\section{Visualization of Effervescent Atomization}

Visualization of the global spray plume, with and without effervescent atomization, was carried out in both a quiescent atmosphere and the supersonicmodel combustorusing a digital video camcorder with a proper backlighting for illumination. Figure 3 demonstrates and compares the typical spray structures of kerosene injection into a quiescent atmosphere, without and with barbotage gas. The baseline cavity module (A) with discharge orifice diameter of $0.6 \mathrm{~mm}$ was employed for the test. For the cases without barbotage gas, comparison of Figs. $3 \mathrm{a}$ and $3 \mathrm{~b}$ illustrates that the spray structure varies with injection pressure. In particular, at low injection pressure $(<1.0 \mathrm{MPa})$ the atomization occurred at $\sim 350 \mathrm{~mm}$ downstream
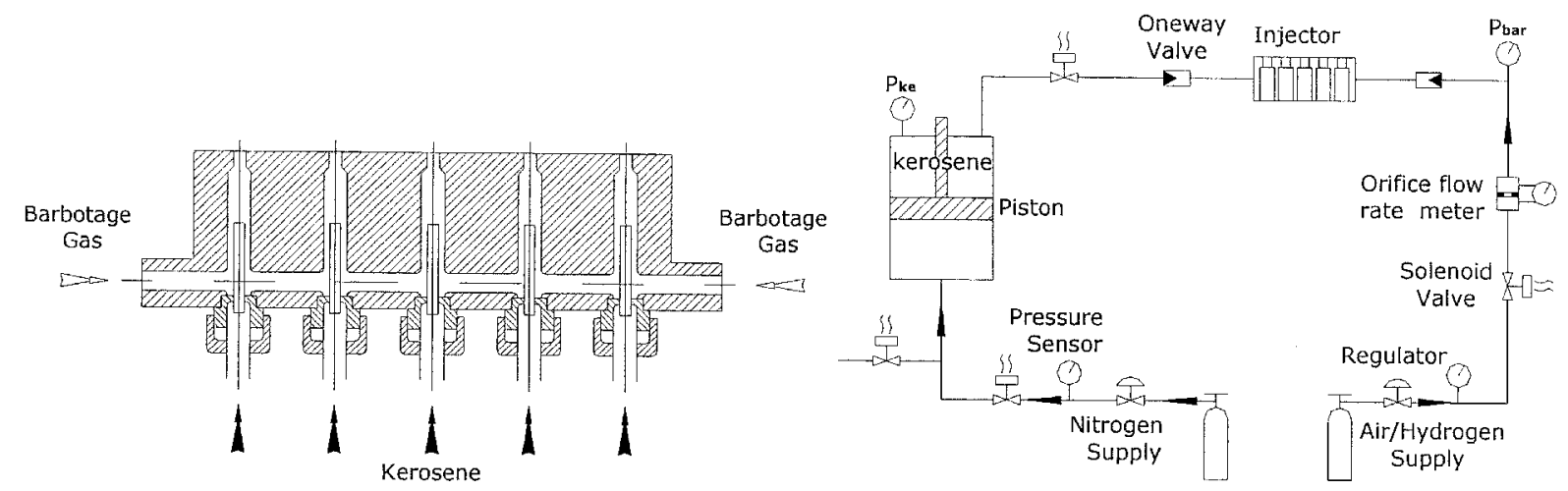

a)

b)

Fig. 2 Schematic of kerosene injection and barbotage system: a) barbotage injectors and b) supply system of liquid kerosene and barbotage gas. 

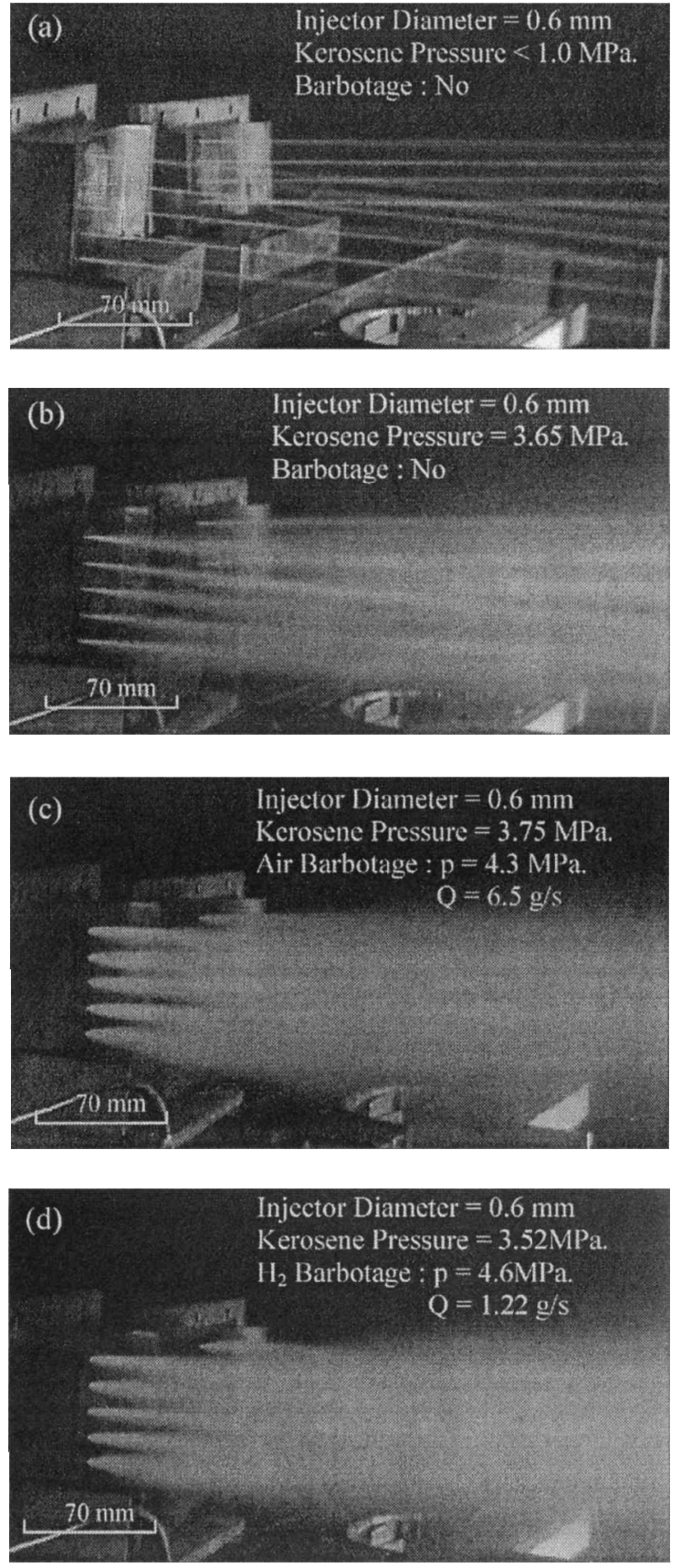

Fig. 3 Images of liquid-kerosene jet issuing into a quiescent atmosphere, comparing the spray structures with and without gas barbotage.

of kerosene injection, as shown in Fig. 3a. As the injection pressure was increased to $3.65 \mathrm{MPa}$, it is seen from Fig. 3b that the overall spray width increases and the atomization behavior improves substantially. On the other hand, for given similar injection pressures Figs. $3 \mathrm{c}$ and $3 \mathrm{~d}$ demonstrate that the global structures of kerosene spray aerated with air and hydrogen appear to behavior similarly. Moreover, with barbotage gas it is seen that the kerosene jets expanded to form blunt cones immediately after the discharge orifice. The diameter of the blunt cone was estimated to be at least 20 times the orifice diameter. Furthermore, the spray structure of the aerated kerosene jet appears to approach homogeneous within $70 \mathrm{~mm}$ downstream of the orifice. The preceding results clearly demonstrate that gas barbotage can facilitate the liquid breakup process and shorten the streamwise distance for optimal atomization.

Spray visualization in the present model combustor was accomplished through the view windows installed on both sides of the kerosene injection station. Two types of windows were designed. The first type consisted of a single quartz window on each sidewall
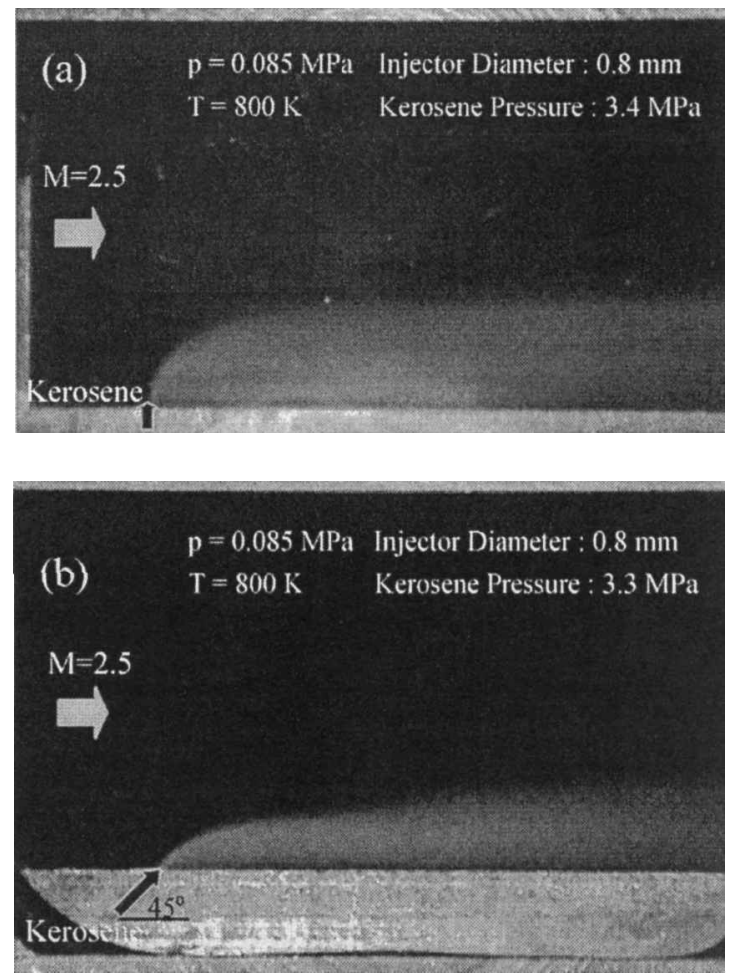

Fig. 4 Images of liquid-kerosene jet in a hot supersonic crossflow: a) normal injection and b) 45-deg injection.
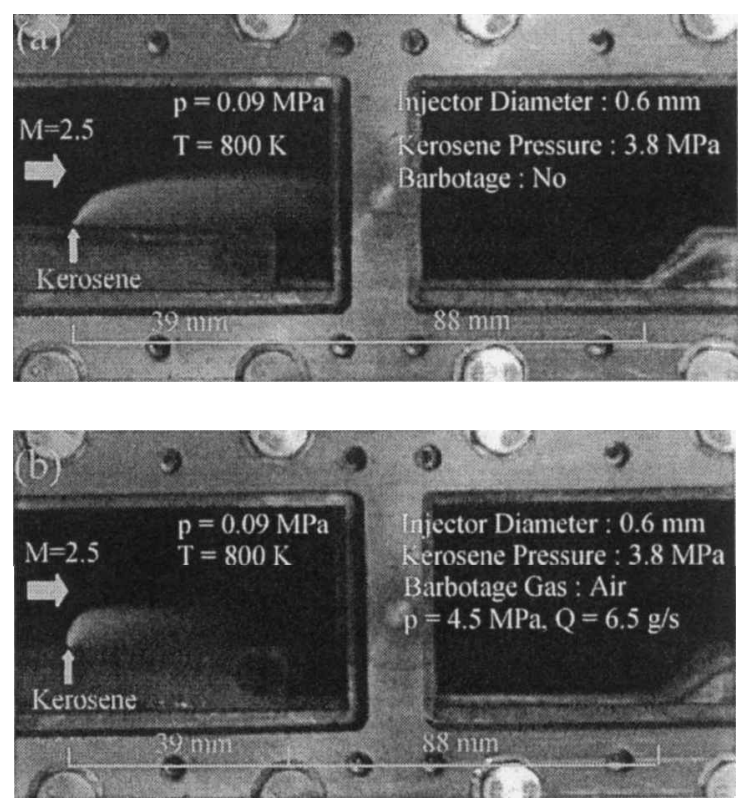

Fig. 5 Images of liquid-kerosene jet issuing into a hot supersonic crossflow: a) pure liquid jet and b) aerated liquid jet.

with $66 \mathrm{~mm}$ in height and $120 \mathrm{~mm}$ in length. For the second type two quartz windows in tandem, with each being of $46 \mathrm{~mm}$ in height and $80 \mathrm{~mm}$ in length, were installed on each side of the combustor. Figure 4 first compares the kerosene spray plumes by using normal injection and angled injection in a supersonic crossflow, under the same flow and injection conditions. Whereas the angled injection might have a smaller total pressure loss, Fig. 4 shows that the corresponding spray penetration height is smaller as compared to that of the normal injection. Because the angled injection led to less kerosene penetration into the hot airstream, it would be less efficient in terms of fuel-air mixing and fast spray evaporation.

Figure 5 further shows the spray structure comparison of pure liquid atomization and effervescent atomization in a supersonic 
crossflow. For both cases kerosene was injected through normal injectors of $0.6 \mathrm{~mm}$ diam with $3.8 \mathrm{MPa}$ injection pressure. Local static temperature was around $800 \mathrm{~K}$, and local static pressure was $0.09 \mathrm{MPa}$. Although the penetration depth in both cases appears to be similar, the overall spray length in the streamwise direction was much shorter with air barbotage and in fact only half of that in the pure liquid atomization case, as shown in Fig. 5. The present results support the previous findings ${ }^{11}$ that with barbotage gas the liquid breakup process is faster, and hence a shorter axial distance is required for fine droplets generation and the subsequent quick evaporation.

\section{Self-Ignition}

Our previous study ${ }^{16}$ demonstrated that the ignition delay of kerosene could be less than $1 \mathrm{~ms}$ when the local temperature is greater than $1280 \mathrm{~K}$. It was estimated ${ }^{16}$ that for the temperature range of 1000-1500 K the evaporation time of a kerosene droplet could be limited to within $1 \mathrm{~ms}$ if the droplet diameter is smaller than $20 \mu \mathrm{m}$. Thus, for the successful self-ignition of a liquid kerosenefueled scramjet system it is essential that the cavity residence time is sufficiently long and larger than the sum of the liquid fuel vaporization time and the ignition delay time.

\section{Experiment Procedure}

The typical tests lasted $7 \mathrm{~s}$ using a preprogrammed sequencer. In the heater the major gases (air, oxygen, and hydrogen) were released $1 \mathrm{~s}$ after a spark ignited the pilot mixture of air and hydrogen. It generally took $\sim 1.5 \mathrm{~s}$ to reach a steady state and achieve the required temperature and pressure. Once the steady Mach 2.5 airflow was established (at $\sim 2.475 \mathrm{~s}$ ), the pilot hydrogen was injected and subsequently self-ignited, if the condition were adequate. It took another $2 \mathrm{~s}$ to achieve a steady burning for the given pilot hydrogen and airflow. Kerosene (with or without barbotage gas) was then injected at $4.5 \mathrm{~s}$. Once the pilot hydrogen flame ignited the kerosene, the overall kerosene burning would be sustained even after the pilot hydrogen was turned off.

\section{Data Analysis}

Following the studies of Yu et al., ${ }^{17,18}$ a one-dimensional model was developed to facilitate the data reduction and the subsequent performance assessment. The details of the one-dimensionalmodel have been documented therein. Based on the measured distribution of static pressure, the flowfield within the combustor was first approximated. This approximated flowfield was then used as an input for the computation of the axial profiles of various flow properties, including Mach number, static pressure, total pressure, static temperature, total temperature, and core flow area. It is noted that the computed flow core area is not necessarily equal to the actual cross-section area of the combustor.

The combustion efficiency is defined herein by the ratio of the static temperature increment between the exit and entrance of combustor to the temperature difference between the correspondingadiabatic flame temperature and the static temperature at the combustor entrance. A simplified one-formula surrogate fuel model,,$^{20}$ with $\mathrm{C}_{12} \mathrm{H}_{24}$ representing kerosene, was adopted. The associated thermodynamic properties taken from Wang, ${ }^{20}$ including heat capacity, enthalpy, and entropy as a function of temperature, were used to calculate the adiabatic flame temperature.

Assuming the pilot hydrogen addition is relatively small and hence is first consumed completely with the available oxygen, the equivalence ratio of pilot hydrogen $\phi_{H}$ is expressed by ${ }^{16}$

$$
\phi_{H}=\left(m_{H} / m_{A}\right) /\left(m_{H} / m_{A}\right)_{\mathrm{st}}
$$

where $m_{H}$ and $m_{A}$ are the mole flow rates of pilot hydrogen and vitiated air, respectively. The subscript st represents the stoichiometric condition, thereby $\left(m_{H} / m_{A}\right)_{\mathrm{st}}=0.418$. Whereas the mean molecular weight of the vitiated air varies with the specific stagnation temperature, the oxygen mole fraction within the resulting vitiated air is the same as that of normal air (20.9\%). Hence, mole flow rates were used to evaluate the fuel equivalenceratio.
Moreover, the effective equivalenceratio of keroseneis expressed by $^{16}$

$$
\phi_{F}=m_{F} /\left[m_{A}-m_{H} /\left(m_{H} / m_{A}\right)_{\mathrm{st}}\right] /\left(m_{F} / m_{A}\right)_{\mathrm{st}}
$$

where $m_{F}$ denotes the mole flow rate of kerosene and $\left(m_{F} / m_{A}\right)_{\mathrm{st}}=$ 0.0116 by approximating kerosene as $\mathrm{C}_{12} \mathrm{H}_{24}$. This expression of the effective equivalence ratio assumes that in order to completely oxidize $m_{H}$ amount of pilot hydrogen $m_{H} /\left(m_{H} / m_{A}\right)_{\text {st }}$ amount of air is required. Therefore, the remaining air, $\left[m_{A}-m_{H} /\right.$ $\left.\left(m_{H} / m_{A}\right)_{\text {st }}\right]$, is used to oxidize the $m_{F}$ amount of kerosene.

\section{Results and Discussion}

\section{Effect of Cavity Flameholder on Combustion Stabilization}

Figure 6 shows the typical static-pressure distribution at the relevant moments, including 1) before the pilot hydrogen ignition (no combustion), 2) after the pilot hydrogen burning, 3) after the kerosene burning, and 4) after pilot hydrogen ceased. The experiment was conducted by using baseline cavity module (A) installed in section I only. Stagnation conditions of the Mach 2.5 flow were stagnation temperature $T_{0}$ of $1810 \mathrm{~K}$ and stagnation pressure $p_{0}$ of $1.06 \mathrm{MPa}$. It is seen from Fig. 6 that steady combustion of kerosene was sustained after pilot hydrogen was turned off. However, the overall static-pressure profile reduced slightly owing to the absence of the additional heat contribution from the pilot hydrogen. Furthermore, the final static pressure was seen to reach an approximately isobaric plateau within Section I of the model combustor and subsequently decrease continuously towards the combustor exit. The relative position of the cavity module is also sketched as a reference. It is seen that the location of fuel injector/flameholder coincides quite well with the regime of isobaric pressure plateau, indicating that the major heat release must take place within the cavity flameholder regime. In addition, the rapid static-pressurereductionbehind the cavity module resulted from both the expansion process in the downstream divergent sections and the decrease in combustion heat release downstream of the cavity flameholder. Figure 6 also shows that the static-pressure profile extended towards the upstream of kerosene injection.

Figure 7 further illustrates the significant effect of cavity flameholder on combustion stabilization. The experiment was conducted by using two baseline cavity modules (A) in tandem, installed in both sections I and II, with flow conditions of $T_{0}=1668 \mathrm{~K}$ and $p_{0}=1.015 \mathrm{MPa}$. The front cavity module was equipped with both kerosene and pilot hydrogen injections, whereas only kerosene injection was installed in the rear one. It is seen from Fig. 7 that there existed two regimes of isobaric pressure plateau, which corresponded well to the locations of two cavity modules (compare the position sketch of the cavity modules in Fig. 7).

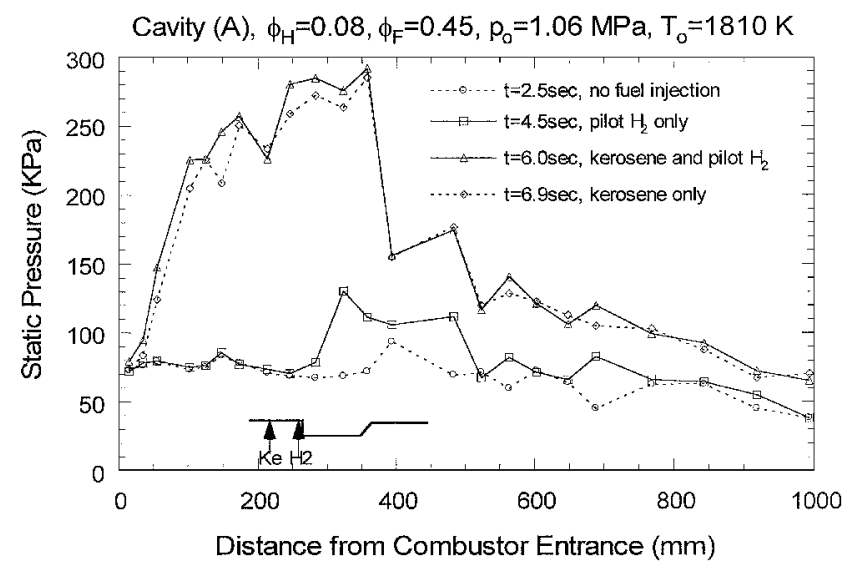

Fig. 6 Typical static-pressure distributions in the axial direction at relevant moments using the baseline cavity module (A). 


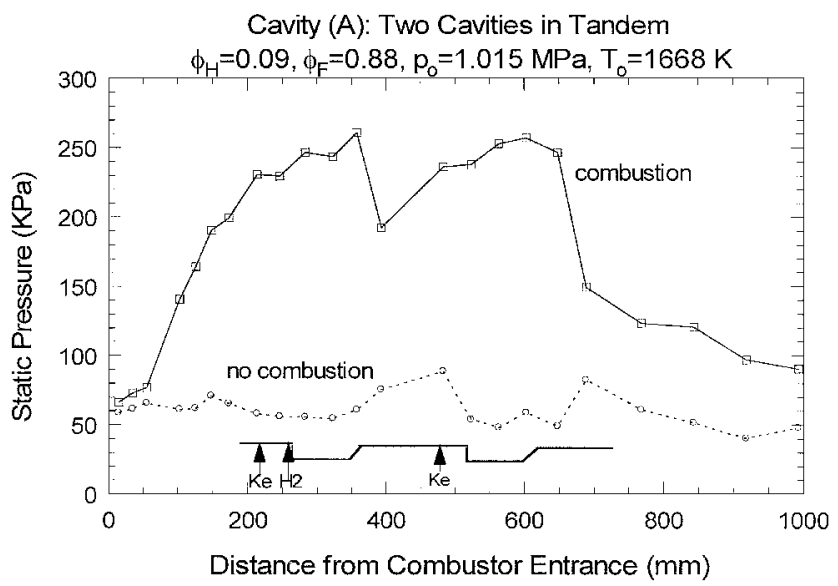

Fig. 7 Typical static-pressure distributions in the axial direction at relevant moments using two baseline cavity modules $(A)$ in tandem.

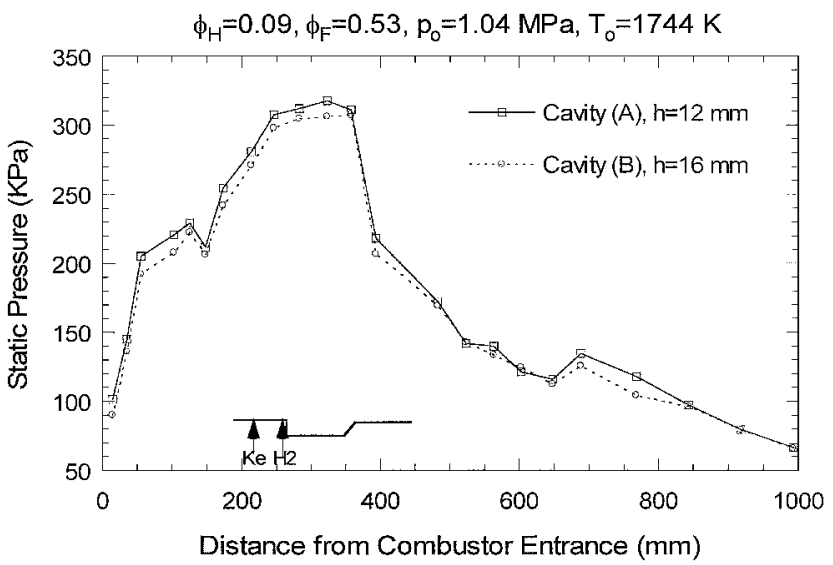

Fig. 8 Comparison of static-pressure distributions in the axial direction using cavity modules (A) and (B), comparing the effect of cavity depth on combustor performance.

\section{Effect of Cavity Depth on Static-Pressure Distribution}

Based on the analysis of nonreacting cavity flows, the cavity depth characterizesthe cavity residence time. Our previous results ${ }^{16}$ demonstrated that the combustion performance was improved by increasing the cavity depth from 8 to $12 \mathrm{~mm}$. We have furtherincreased the cavity depth to $16 \mathrm{~mm}$ and compared its performance with that of $12 \mathrm{~mm}$ cavity depth. Figure 8 shows such a comparison using cavity modules (A) and (B) under the same air/fuels flow conditions, with $T_{0}=1744 \mathrm{~K}, p_{0}=1.04 \mathrm{MPa}, \phi_{F}=0.53$, and $\phi_{H}=0.09$. Experimental results showed that the static-pressure profiles were essentially the same (within the experimentaluncertainty) with $h=12$ and $16 \mathrm{~mm}$. Although the enhancementeffects of cavity depth seems to saturate when $h>12 \mathrm{~mm}$, the strong interactions among the pilot hydrogen flame, kerosene spray, and the flow recirculation inside the recessed cavity merit further studies. In particular, the interactions are also complicated by the presence of the oblique shock train and expansion waves within the cavity.

\section{Effect of Effervescent Atomization on Combustion Performance}

It has been shown in the study of Lin et al. ${ }^{11}$ that the structure and performance of effervescent atomization depend on the imposing pressures of liquid and barbotage gas as well as their relative mass ratio. To demonstrate the steadiness of the present barbotage system, Fig. 9 compares the measured profiles of static pressure obtained from various runs under approximately the same conditions. The baseline cavity module (A) was employed, with $\phi_{F}=0.44$, $\phi_{H}=0.09$, and hydrogen barbotage of $1.22 \mathrm{~g} / \mathrm{s}$. Although Fig. 9 shows that the experimental data were quite reproducible (within the experimental uncertainty), the overall system response was less

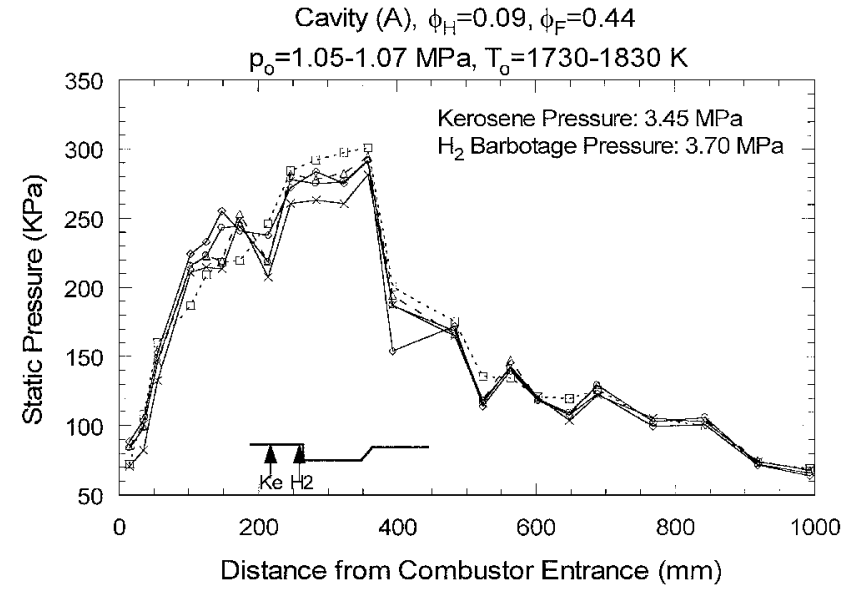

Fig. 9 Static-pressure distributions in the axial direction under similar experimental conditions using cavity module (A) with hydrogen barbotage.

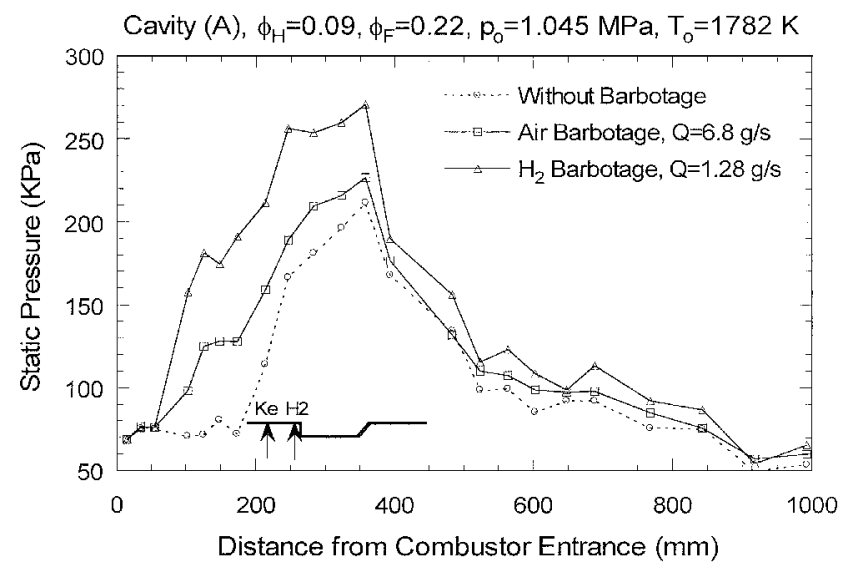

Fig. 10 Comparison of static-pressure distributions without and with gas barbotage using cavity module (A).

stable as compared to the cases with pure liquid-keroseneinjection. Further examinations indicated that the stability and repeatability are sensitive to the operation conditions of effervescent atomization. Nevertheless, the present data of effervescent atomization are considered to be of representative, although various improvements to the barbotage system are currently underway.

Figure 10 compares the performance of kerosene combustion aerated with either air or hydrogen using the baseline cavity module (A), with $\phi_{F}=0.22$ and $\phi_{H}=0.09$. The mass-flow rates of barbotage air and barbotage hydrogen were 6.8 and $1.28 \mathrm{~g} / \mathrm{s}$, respectively. The data obtained using pure kerosene injection are also included in Fig. 10 for comparison. Under the same operation conditions, results generally show that the aerating effect of barbotage gas facilitates the overall burning. Moreover, hydrogen barbotage leads to a better combustor performance than air barbotage. In particular, the peak plateau pressure yielded by using hydrogen barbotage is $20-25 \%$ higher than that obtained using pure liquid atomization, for the conditions tested. This substantiates our earlier expectation that effervescent atomization can greatly enhance fuel-air mixing and facilitate the generation of fine droplets for fast evaporation. Additionally, the use of hydrogen barbotage further generates more heat release to promote the global burning.

\section{Effect of Angled Injection on Combustion Performance}

Figure 11 shows the static-pressure profiles obtained by using normal and angled injections, namely cavity modules (A) and (C), respectively. The flow conditions were $T_{0}=1780 \mathrm{~K}, p_{0}=1.02 \mathrm{MPa}$, $\phi_{F}=0.22$, and $\phi_{H}=0.10$. It is seen from Fig. 11 that normal injection yielded a better combustion performance than that using angled 


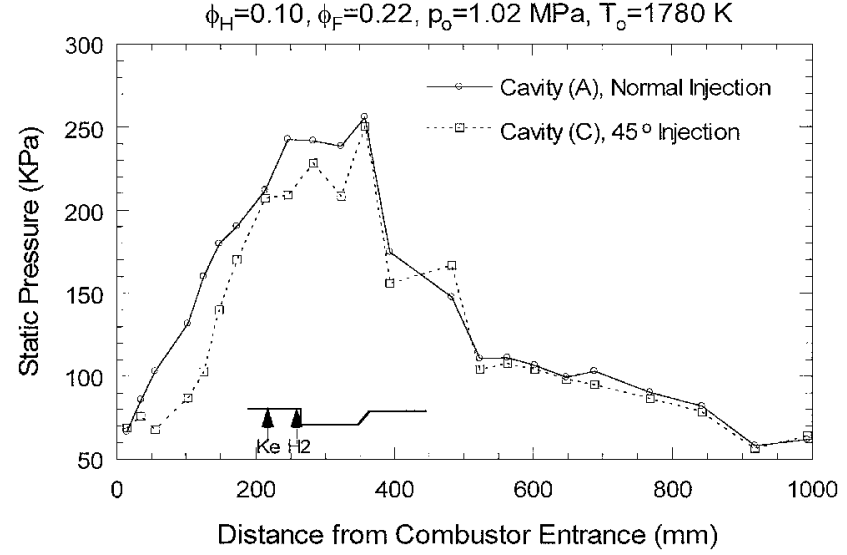

Fig. 11 Comparison of static-pressure distributions using normal injection and 45-deg injection.

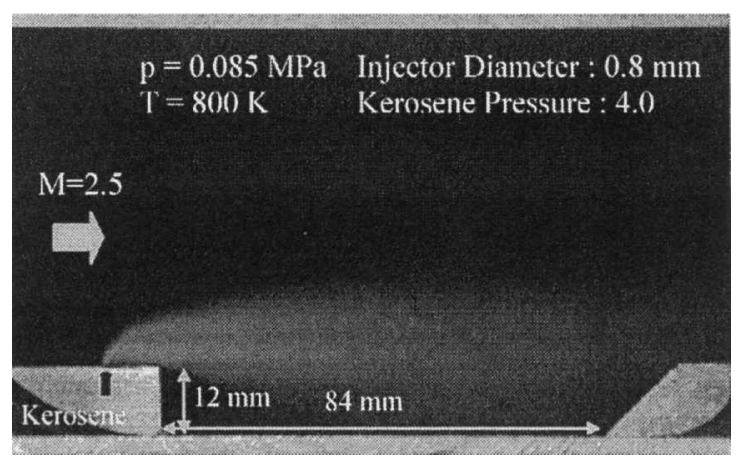

Fig. 12 Image of liquid-kerosene jet issuing into a hot supersonic crossflow.

injection. This finding is consistent with the spray visualizationcompared in Fig. 4 that normal injection yielded a deeper fuel penetration. However, the angled injection scheme might hold a potential of reducing total pressureloss. We will discuss this further when assessing the performances of various fuel-injector/flameholder modules in a later section.

\section{Cavity Characteristics}

It has been recognized that the effects of cavity on mixing and combustion stabilization can be quite disparate depending on whether the cavity is open or closed. Generally speaking, stable cavity could be used for flameholding purpose, whereas unstable cavity could be applied for mixing enhancement. Because the conventional definition of the cavity characteristics was based on the nonreacting flows and our previous results ${ }^{16}$ have suggested that the existing definition is subject to revision in the reacting cases, we have carried out the following experiments to address the preceding important issues.

Figure 12 shows the spray structure of a pure liquid-kerosene jet in a hot supersonic crossflow, using a fuel-injector/flameholder module with normal fuel injection upstream of the cavity. The local conditions of the Mach 2.5 airflow were $p=0.085 \mathrm{MPa}$ and $T=800 \mathrm{~K}$, thereby eluding self-ignition of kerosene. Kerosene was injected from the injectors of $0.8 \mathrm{~mm}$ diam and with injection pressure of 4.0 MPa. Moreover, the cavity depth and length were 12 and $84 \mathrm{~mm}$, respectively. Basing on the conventionaldefinition, the present cavity with $L / h=7$ is characterized as an open cavity. Being an open cavity, the shear layer shed from the leading edge of cavity is supposed to move across the cavity without impinging on the cavity floor. However, Fig. 12 clearly illustrates that the spray was deflected towards the bottom floor of the cavity, even starting from the very beginning of the cavity. Therefore, in spite of $L / h=7$ the present cavity exhibits "closed" characteristics with kerosene normal injection.

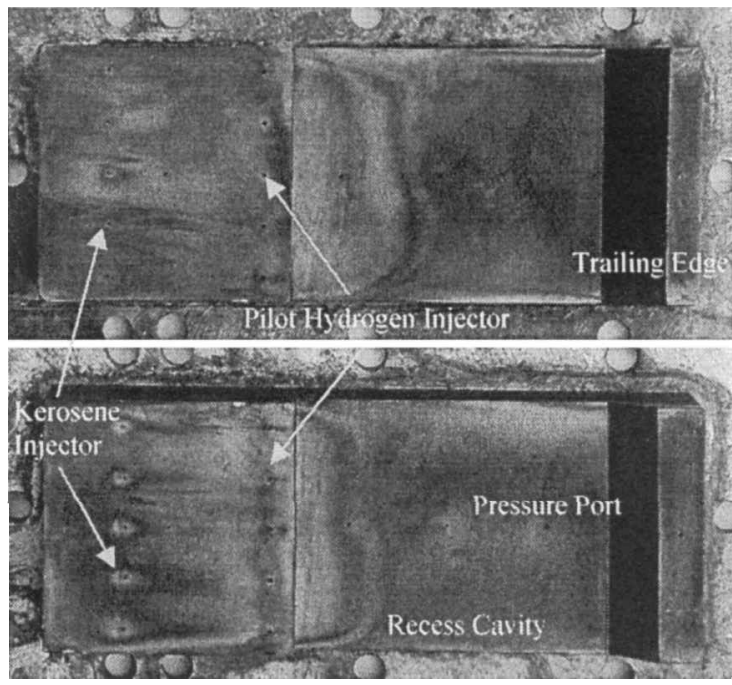

Fig. 13 Direct photographs of the baseline cavity pair after several experimental runs.

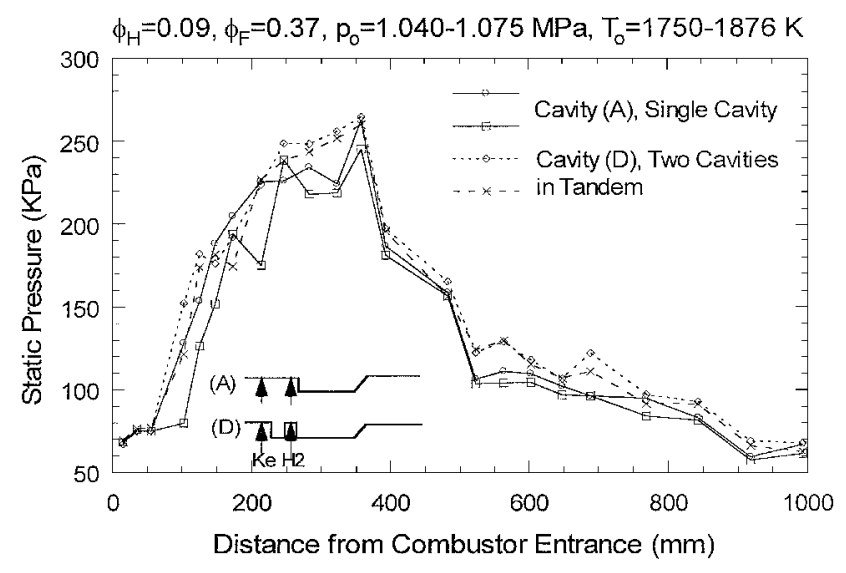

Fig. 14 Comparison of static-pressure distributions using the baseline cavity module (A) and cavity module (D).

Figure 13 further demonstrates direct images of the baseline cavity pair posterior to supersonic combustion experiments. In this run kerosene and pilot hydrogen were injected upstream of the cavity. Photographs in Fig. 13 show that the temperature distribution in the cavity was extremely nonuniform. In particular, the temperature in the recirculation zone was low because the local surface color was almost unchanged before and after the experiments. However, there was severe change in the surface color in the local stagnation region near the aft-slanted wall, thereby implying a localized high temperature therein. This result demonstrated that the reacting spray impinged somewhere on the cavity floor rather than the aft wall and thus induced a local high-temperature region. This local high-temperature region would be the major factor in promoting the ignition and the subsequent flameholding of the kerosene combustion. Because this module also behaved like a closed cavity, the threshold value of the length to depth ratio defining a closed cavity should be no more than $5 \sim 7$ for reacting flows.

Figure 14 compares the performances of the baseline cavity module (A) and cavity module (D) with open and a closed cavities in tandem. The flow conditions were similar, and the equivalenceratios of kerosene and pilot hydrogen were kept constant. Based on the measured profiles of static pressure obtained from various runs, the use of the combined open-closed cavities seems to yield a slightly better combustion performance.

Figure 15 shows a comparison of static-pressure distribution using cavity modules (D) and (E) with $T_{0}=1738 \mathrm{~K}, p_{0}=1.025 \mathrm{MPa}$, $\phi_{F}=0.49$, and $\phi_{H}=0.09$. The experiment was conducted by 
Table 1 Experimental condition and combustor performance

\begin{tabular}{|c|c|c|c|c|c|c|c|c|c|c|c|c|c|c|}
\hline \multirow{2}{*}{$\begin{array}{l}\text { Cavity } \\
\text { module }\end{array}$} & \multicolumn{3}{|c|}{ Airflow conditions } & \multicolumn{3}{|c|}{ Pilot $\mathrm{H}_{2}$ conditions } & \multicolumn{3}{|c|}{ Kerosene conditions } & \multicolumn{2}{|c|}{$\begin{array}{l}\text { Barbotage gas } \\
\text { mass-flow rate }\end{array}$} & \multirow{2}{*}{$\begin{array}{c}\text { Combustion } \\
\text { efficiency } \\
\eta, \%\end{array}$} & \multicolumn{2}{|c|}{$\begin{array}{c}\text { Total pressure } \\
\text { recovery }\end{array}$} \\
\hline & $T_{0}, \mathrm{~K}$ & $p_{0}, \mathrm{MPa}$ & $Q, \mathrm{~g} / \mathrm{s}$ & $p, \mathrm{MPa}$ & $Q, \mathrm{~g} / \mathrm{s}$ & $\phi_{H}$ & $p, \mathrm{MPa}$ & $Q, \mathrm{~g} / \mathrm{s}$ & $\phi_{F}$ & $Q_{\mathrm{H} 2}, \mathrm{~g} / \mathrm{s}$ & $\mathrm{Q}_{\text {Air }}, \mathrm{g} / \mathrm{s}$ & & Cal & Exp \\
\hline A & 1735 & 1.035 & 1267 & 4.40 & 4.04 & 0.1 & 2.60 & 53.38 & 0.53 & 0 & 0 & 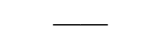 & - & 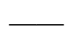 \\
\hline B & 1752 & 1.045 & 1268 & 4.00 & 3.67 & 0.09 & 2.30 & 53.99 & 0.53 & 0 & 0 & & & \\
\hline A & 1721 & 1.025 & 1260 & 4.30 & 3.94 & 0.10 & 1.95 & 45.96 & 0.44 & 0 & 0 & 57 & 0.44 & 0.43 \\
\hline B & 1815 & 1.065 & 1271 & 3.90 & 3.58 & 0.09 & 1.90 & 46.09 & 0.46 & 0 & 0 & 60 & 0.44 & \\
\hline A & 1746 & 1.030 & 1255 & 3.80 & 3.48 & 0.09 & 3.30 & 32.35 & 0.32 & 0 & 0 & 66 & 0.44 & \\
\hline B & 1853 & 1.100 & 1293 & 3.75 & 3.44 & 0.08 & 3.60 & 34.53 & 0.32 & 0 & 0 & 74 & 0.44 & \\
\hline A & 1790 & 1.040 & 1248 & 4.20 & 3.85 & 0.10 & 0.50 & 24.08 & 0.23 & 0 & 0 & 68 & 0.47 & 0.49 \\
\hline A & 1751 & 1.050 & 1276 & 5.30 & 4.86 & 0.11 & 3.05 & 24.08 & 0.23 & 0 & 6.8 & 87 & 0.43 & 0.46 \\
\hline A & 1812 & 1.050 & 1251 & 4.70 & 4.31 & 0.10 & 3.58 & 22.50 & 0.22 & 1.28 & 0 & 89 & 0.46 & 0.46 \\
\hline B & 1777 & 1.030 & 1240 & 3.40 & 3.12 & 0.08 & 0.86 & 32.35 & 0.32 & 0 & 0 & 71 & 0.44 & \\
\hline A & 1827 & 1.030 & 1220 & 4.00 & 3.67 & 0.10 & 3.54 & 31.25 & 0.31 & 0 & 6.5 & 76 & 0.45 & 0.43 \\
\hline A & 1928 & 1.090 & 1252 & 4.70 & 4.31 & 0.11 & 3.65 & 32.95 & 0.32 & 1.25 & 0 & 86 & 0.44 & 0.43 \\
\hline B & 1815 & 1.065 & 1271 & 3.90 & 3.58 & 0.09 & 1.90 & 46.09 & 0.44 & 0 & 0 & 61 & 0.44 & \\
\hline A & 1839 & 1.060 & 1249 & 5.20 & 4.77 & 0.10 & 3.55 & 45.60 & 0.44 & 0 & 6.1 & 70 & 0.42 & \\
\hline A & 1815 & 1.080 & 1272 & 3.70 & 3.39 & 0.08 & 3.56 & 48.40 & 0.46 & 1.22 & 0 & 76 & 0.42 & 0.45 \\
\hline A & 1825 & 1.04 & 1237 & 4.40 & 4.04 & 0.10 & 1.15 & 36.84 & 0.36 & 0 & 0 & 70 & 0.43 & 0.43 \\
\hline A & 1807 & 1.045 & 1248 & 4.40 & 4.04 & 0.10 & 1.30 & 38.06 & 0.38 & 0 & 0 & 65 & 0.43 & 0.44 \\
\hline D & 1751 & 1.055 & 1285 & 4.10 & 3.76 & 0.09 & 1.90 & 36.24 & 0.36 & 0 & 0 & 76 & 0.42 & 0.43 \\
\hline D & 1876 & 1.075 & 1256 & 4.10 & 3.76 & 0.09 & 1.85 & 38.91 & 0.38 & 0 & 0 & 72 & 0.43 & 0.43 \\
\hline B & 1786 & 1.025 & 1230 & 3.40 & 3.11 & 0.09 & 1.80 & 46.20 & 0.45 & 0 & 0 & 67 & 0.41 & L \\
\hline A & 1721 & 1.025 & 1260 & 4.30 & 3.94 & 0.10 & 1.95 & 45.96 & 0.44 & 0 & 0 & 57 & 0.44 & 0.43 \\
\hline D & 1895 & 1.065 & 1250 & 5.30 & 4.86 & 0.11 & 3.20 & 45.60 & 0.44 & 0 & 0 & 82 & 0.40 & \\
\hline D & 1828 & 1.065 & 1263 & 4.10 & 3.76 & 0.09 & 3.10 & 46.82 & 0.46 & 0 & 0 & 79 & 0.41 & 0.41 \\
\hline
\end{tabular}

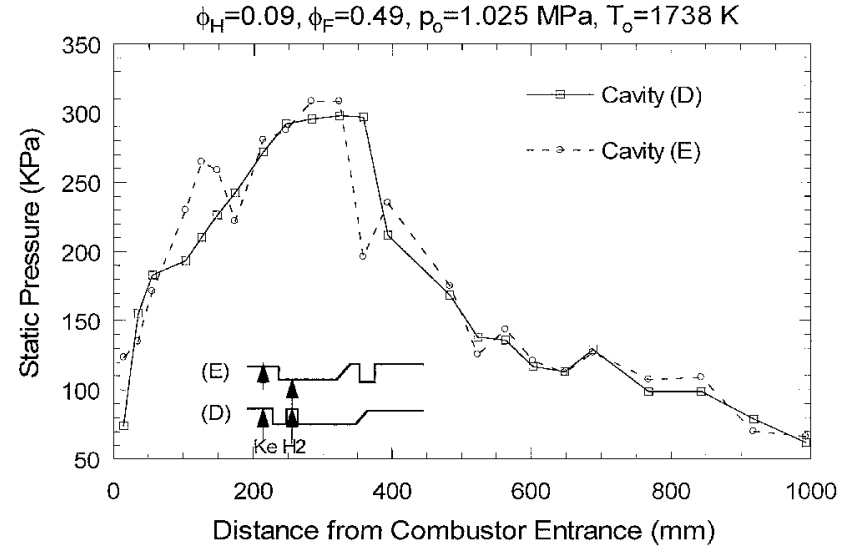

Fig. 15 Comparison of static-pressure distributions using cavity modules (D) and (E), with combined open and closed cavities.

using pure liquid-kerosene injection along with pilot hydrogen. As sketched in Fig. 1, cavity module (E) differs from cavity module (D) in terms of the arrangement of open and closed cavities. In addition, for cavity module (E) the injection station of pilot hydrogen was located at the floor of the leading closed cavity. It is seen that the performance of cavity module (E) seems to be slightly better by comparing the static-pressure distributions. It was also found that the self-ignition of kerosene was facilitated when the pilot hydrogen injection was located at the cavity floor than upstream of the cavity. Specifically, the minimally required pilot hydrogen equivalence ratio $\phi_{H, \min }$ can be as low as 0.04 for the use of cavity module (E). This implies that the pilot hydrogen flame also needs a sufficient residence time to fully develop in order for the production of a pool of heat and radicals, which can then effect kerosene ignition. Otherwise, the cold kerosene spray would quench the immature pilot hydrogen flame.

Figure 16 compares the combustion performances of cavity module (E) and the baseline cavity module (A) with $T_{0}=1748 \mathrm{~K}$, $p_{0}=1.02 \mathrm{MPa}, \phi_{F}=0.23$, and $\phi_{H}=0.09$. Kerosene was barbotaged with hydrogen herein. It is seen from Fig. 16 that cavity (E) leads to higher peak static pressure and better combustion performance.

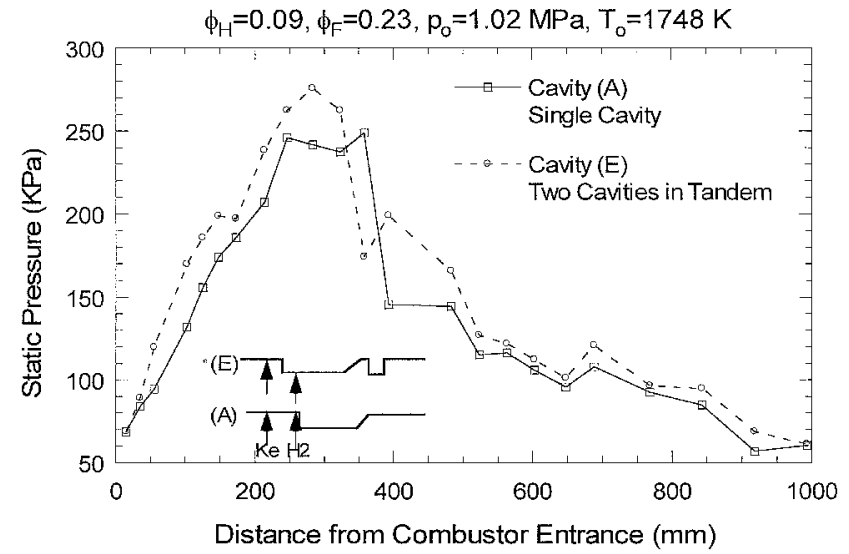

Fig. 16 Comparison of static-pressure distributions using the baseline cavity module (A) and cavity module (E).

\section{Combustion Efficiency and Total Pressure Recovery}

The experiment conditions and combustion performances of various runs associated with Figs. 8, 10, and 14 are listed and summarized in Table 1. Stagnation temperature ranged from 1700 to $1900 \mathrm{~K}$, whereas stagnation pressure was kept around 1.0 to 1.1 MPa. Recognizing that the flow within the supersonic combustor is extremely complex and is highly turbulent in nature, the onedimensional model employed herein aims to gain qualitative understanding of the dominant physical processes in supersonic combustion. We have found that the approximate flowfield yielded by this simplified one-dimensional model is generally consistent with the experimental observation. Because the key combustor performance parameters, such as combustion efficiency and total pressure recovery, were deduced based on the measured static-pressure distribution, the associateduncertaintieswere estimated by varying the input static-pressure profile within the experimental uncertainty. Statistical analysis showed that the uncertainties for combustion efficiency and total pressure recovery are around 6 and 4\%, respectively.

For the first six experiments related to Fig. 8, it is seen that when $h>12 \mathrm{~mm}$ the effect of cavity depth is insignificant and the combustion efficiencies and total pressure recoveriescaused by different cavity depths were similar. The next nine runs corresponded to 
Fig. 10, in which the case of $\phi_{F}=0.22$ along with hydrogen barbotage showed the highest combustion efficiency of $89 \%$. Moreover, the lowest combustion efficiency of $61 \%$ occurred in the case of pure liquid atomization with $\phi_{F}=0.44$. For the conditions investigated the use of hydrogen barbotage increased the combustion efficiency by $15-20 \%$ as compared to the pure liquid atomization cases. For the last eight runs corresponding to Fig. 14, the module with combined open and closed cavities generally had $10 \%$ higher combustion efficiency than the baseline cavity module.

It was also found that with 45-deg injection the combustion efficiency was approximately $10 \%$ lower than that with normal injection. However, the total pressure recovery improved in the case with angled injection. We further note that the estimated total pressure recovery using the one-dimensional model agreed well with the measured one, as shown in Table 1.

\section{Summary}

Combustion stabilization and ignition enhancement in a liquidkerosene-fueledmodel combustor of cross section $51 \times 70 \mathrm{~mm}$ were systematically investigated utilizing the concepts of effervescent atomization, with either air or hydrogen being a barbotage gas, and cavity-based flameholder. The entry Mach number was fixed at 2.5. The total pressure of vitiated air varied around 1.0-1.3 $\mathrm{MPa}$, and the total temperature ranged from 1700-1900 K.

Barbotaged atomization by using hydrogen was shown to promote the overall burning and increase the combustion efficiency by 15 $20 \%$ comparing to the pure liquid atomization case. However, it has to be recognized that the extent of combustionenhancementstrongly depends on the operation condition of effervescent atomization.

In general, combustion performance was found to increase with increasing cavity depth, which essentially characterizes the cavity residence time. It was found that for the given design of cavity flameholder the combustion performance does not vary much with further increasing the cavity depth from $12 \mathrm{~mm}$. In terms of the cavity characteristics, the threshold value of the length-to-depth ratio defining a closed cavity should be no more than $5 \sim 7$ for reacting flows. In addition, the configuration with an open and a closed cavities in tandem was shown to have a better performance than the one with a single closed cavity. Further study in this regard is warranted.

The present experimental results also substantiate our previous finding that there existed a local high-temperature region, which serves as a source of thermal energy and active chemical radicals for promoting the initiation and the subsequent flameholding of the kerosene combustion.

Furthermore, the experimental investigation demonstrated that injection location and injection scheme have significant effects on the minimally required pilot hydrogen equivalence ratio. It is of importance for the pilot hydrogen flame to fully develop so that a sufficiently strong pool of heat and radicals is available for effecting kerosene ignition.

\section{Acknowledgments}

The research program of the Chinese Academy of Sciences was supported by the National Natural Science Foundation of China under Contract 10232060 . C. J. Sung was supported by the Case School of Engineering through the Case Alumni Association. The authors would also like to acknowledge D. X. Qian and Y. Li for their assistance in experimental preparations as well as L. J. Yue and F. Cheng for the help of data reduction.

\section{References}

${ }^{1}$ Tishkoff, J. M., Drummond, J. P., Edwards, T., and Nejad, A. S., "Future Direction of Supersonic Combustion Research: Air Force/NASA Workshop on Supersonic Combustion,” AIAA Paper 97-1017, Jan. 1997.

${ }^{2}$ Curran, E. T., and Murthy, S. N. B., Scramjet Propulsion, Progress in Astronautics and Aeronautics, Vol. 189, AIAA, Reston, VA, 2001, Chap. 12.

${ }^{3}$ Avrashkov, V., Baranovsky, S., and Levin, V., "Gasdynamic Features of Supersonic Kerosene Combustion in a Model Combustor Chamber," AIAA Paper 90-5268, Oct. 1990.

${ }^{4}$ Kay, I. W., Peschke, W. T., and Guile, R. N., "Hydrocarbon-Fueled Scramjet Combustor Investigation,' Journal of Propulsion and Power, Vol. 8, No. 2, 1992, pp. 507-512.

${ }^{5}$ Vinogradov, V., Kobigsky, S., and Petrov, M., "Experimental Investigation of Liquid Hydrocarbon-Hydrogen Fuel Combustion in Channel at Supersonic Velocities,” AIAA Paper 92-3429, July 1992.

${ }^{6}$ Bonghi, L., Dunlap, M. J., Owens, M. G., Young, C., and Segal, C., "Hydrogen Piloted Energy for Supersonic Combustion of Liquid Fuels," AIAA Paper 95-0730, Jan. 1995.

${ }^{7}$ Owens, M. G., Tehranian, S., Segal, C., and Vinogradov, V., "Flameholding Configurations for Kerosene Combustion in a Mach 1.8 Airflow," Journal of Propulsion and Power, Vol. 14, No. 4, 1998, pp. 456-461.

${ }^{8} \mathrm{Yu}, \mathrm{K}$., Wilson, K. J., and Schadow, K. C., "Effect of Flame-Holding on Supersonic-Combustion Performance," Journal of Propulsion and Power, Vol. 17, No. 6, 2001, pp. 1287-1295

${ }^{9}$ Baurle, R. A., and Gruber, M. R., "A Study of Recessed Cavity Flowfields for Supersonic Combustion Applications,” AIAA Paper 98-0938, Jan. 1998.

${ }^{10}$ Mathur, T., Gruber, M., Jackson, K., Donbar, J., Donaldson, W., Jackson, T., and Billig, F., "Supersonic Combustion Experiments with a Cavity-Based Fuel Injector," Journal of Propulsion and Power, Vol. 17, No. 6, 2001, pp. 1305-1312.

${ }^{11}$ Lin, K.-C., Kirkendall, K. A., Kennedy, P. J., and Jackson, T. A., "Spray Structures of Aerated Liquid Fuel Jets in Supersonic Cressflows," AIAA Paper 99-2374, June 1999.

${ }^{12}$ Mathur, T., Lin, K.-C., Kennedy, P. J., Gruber, M., Donbar, J., Jackson, T., and Billig, F., "Liquid JP-7 Combustion in a Scramjet Combustor," AIAA Paper 2000-3581, July 2000.

${ }^{13}$ Li, J. G., Yu, G., Zhang, X. Y., and Huang, Q. S., "Combustion of Kerosene in a Supersonic Stream,” AIAA Paper 2000-0615, Jan. 2000.

${ }^{14}$ Hsu, K.-Y., Carter, C., Crafton, J., Gruber, M., Donbar, J., Mathur, T., Schommer, D., and Terry, W., "Fuel Distribution About a Cavity Flameholder in Supersonic Flow," AIAA Paper 2000-3585, July 2000.

${ }^{15}$ Burnes, R., Parr, T. P., Wilson, K. J., and Yu, K., "Investigation of Supersonic Mixing Control Using Cavities: Effect of Fuel Injection Location," AIAA Paper-2000-3618, July 2000.

${ }^{16}$ Yu, G., Li, J. G., Chang, X. Y., Chen, L. H., and Sung, C. J., "Investigation of Kerosene Combustion Characteristics with Pilot Hydrogen in Model Supersonic Combustors," Journal of Propulsion and Power, Vol. 17, No. 6, 2001, pp. 1263-1272.

${ }^{17}$ Yu, G., Li, J. G., Zhao, J. R., Han, B., Chang, X. Y., and Qian, D. X., "Experimental Studies on $\mathrm{H}_{2}$ /Air Model Scramjet Combustor," AIAA Paper 99-2449, June 1999.

${ }^{18}$ Yu, G., Li, J. G., Zhang, X. Y., Chen, L. H., Han, B., and Sung, C. J., "Experimental Investigation on Flameholding Mechanism and Combustion Performance in Hydrogen-Fueled Supersonic Combustors," Combustion Science and Technology, Vol. 174, No. 3, 2002, pp. 1-27.

${ }^{19}$ Li, J. G., Yu, G., Zhang, Y., Li, Y., and Qian, D. X., "Experimental Studies on Self-Ignition of Hydrogen/Air Supersonic Combustion,' Journal of Propulsion and Power, Vol. 13, No. 4, 1997, pp. 538-542.

${ }^{20}$ Wang, T.-S., "Thermo-Kinetics Characterization of Kerosene/RP-1 Combustion,” AIAA Paper 96-2887, July 1996. 